\title{
The microrna 29 family and its regulation
}

\author{
Le Thi Truc Linh ${ }^{1 *}$ \\ ${ }^{1}$ Ho Chi Minh City Open University, Vietnam \\ "Corresponding author: linh.ltt@ou.edu.vn
}

\begin{abstract}
ARTICLE INFO
ABSTRACT

DOI: $10.46223 /$ HCMCOUJS. tech.en.8.1.332.2018

Received: February $6^{\text {th }}, 2018$

Revised: March $14^{\text {th }}, 2018$

Accepted: April 16 ${ }^{\text {th }}, 2018$

Keywords:

growth factors, microRNAs, MiR-29 family, transcription factors

Since miRNAs have broad effects on tissue homeostasis and disease development, it is particularly interesting to work out how miRNAs themselves are being regulated. Such data could provide crucial information for further understanding the mechanism underlying disease development and for being able to manipulate these miRNAs therapeutically. Generally, the expression of miRNAs can be regulated transcriptionally, epigenetically, or controlled by different stimuli e.g., cytokines and growth factors. In review, just transcription factors, cytokines, and growth factors controlling the miR-29 family expression in human diseases were for the first time investigated.
\end{abstract}

\section{Introduction}

MicroRNAs are an abundant class of evolutionarily conserved, short ( 22nt long), single-stranded RNA molecules that have recently emerged as important post-transcriptional regulators of gene expression by binding to specific sequences within a target mRNA (Ambros, 2004; Bartel, 2004). To date, 1424 miRNAs have been identified in human cells and each was predicted to regulate several target genes (Kozomara \& Griffiths-Jones, 2011; Lim et al., 2005). Computational predictions indicate that more than $50 \%$ of all human protein-coding genes are potentially regulated by miRNAs (Friedman, Farh, Burge, \& Bartel, 2009; Lewis, Burge, \& Bartel, 2005). The abundance of mature miRNAs varies extensively from as few as ten to more than 80,000 copies in a single cell, which provides a high degree of flexibility in the regulation of gene expression (Chen et al., 2005; Suomi et al., 2008). The regulation exerted by miRNAs is reversible, as feedback/forward regulatory loops have been shown to exert modifying effects during translation (Inui, Martello, \& Piccolo, 2010).

\section{MicroRNA biogenesis}

Despite the obvious differences between the biology of miRNAs and mRNAs, all available evidence suggests that these transcripts share common mechanisms of transcriptional regulation. Generally, the generation of a miRNA is a multi-step process that starts in the nucleus and finishes in the cytoplasm (Lee, Jeon, Lee, Kim, \& Kim, 2002). Firstly, miRNAs are transcribed by the RNA polymerase II complex (Lee et al., 2004) and subsequently capped, polyadenylated, and spliced (X. Cai, Hagedorn, \& Cullen, 2004). Transcription results in a primary miRNA transcript (prior-miRNA) that harbors a hairpin structure (Kim, 2005; Lee et al., 2002). Within the nucleus, the RNAse II-type molecule Drosha and its cofactor DGCR8 
process the pri-miRNAs into 70- to 100-nt-long pre-miRNA structures (Han et al., 2004; Lee et al., 2003), which in turn are exported to the cytoplasm through the nuclear pores by Exportin5 (Bohnsack, Czaplinski, \& Gorlich, 2004; Lund, Güttinger, Calado, Dahlberg, \& Kutay, 2004; Yi, Qin, Macara, \& Cullen, 2003; Zeng \& Cullen, 2004). Subsequently, the RNAse III-type protein Dicer generates a double-stranded short RNA in the cytoplasm that consists of the leading-strand miRNA and its complementary sequence (Chendrimada et al., 2005; Grishok et al., 2001; Hutvagner et al., 2001; Ketting et al., 2001). This duplex miRNA is unwound by a helicase into a single-stranded short RNA in the cytoplasm and the leading strand is incorporated into the argonaute protein (Ago 2)-containing ribonucleoprotein complex known as the miRNA-induced silencing complex, mRISC (Bossé \& Simard, 2010; Hammond, Bernstein, Beach, \& Hannon, 2000; Hutvagner \& Simard, 2008). During this process, one strand of the miRNA duplex is selected as the guide miRNA and remains stably associated with mRISC, while the other strand, known as the passenger strand is rapidly removed and degraded (Martinez, Patkaniowska, Urlaub, Lührmann, \& Tuschl, 2002). The selection of the appropriate strand is primarily determined by the strength of base pairing at the ends of the miRNA duplex. The strand with less-stable base pairing at its 5' end is usually destined to become the mature miRNA (Hutvagner, 2005; Khvorova, Reynolds, \& Jayasena, 2003; Schwarz et al., 2003). However, some miRNA passenger strands are thought to negatively regulate gene expression. One hypothesis is that both strands could be used differently in response to extracellular or intracellular cues, to regulate a more diverse set of protein-encoding genes as needed, or strand selection could be tissue-specific (Ro, Park, Young, Sanders, \& Yan, 2007). The mature miRNA guides the RISC complex to the 3'UTR of its target miRNA (Bartel, 2009; Lai, 2002). The seed sequence, comprising nucleotides 2-8 at 5'-end of the mature miRNA, is important for binding the miRNA to its target site in the mRNA (Lewis et al., 2005). Association of miRNA with its target results in mRNA cleavage (if sequence complementarity is high) or more usually in higher eukaryotes, blockade of translation (Zeng \& Cullen, 2004) (see below).

In an alternative pathway for miRNA biogenesis, short hairpin introns termed mirtrons are spliced and debranched to generate pre-miRNA hairpin mimics (Berezikov, Chung, Willis, Cuppen, \& Lai, 2007; Okamura, Hagen, Duan, Tyler, \& Lai, 2007; Ruby, Jan, \& Bartel, 2007; Sibley et al., 2012; Westholm \& Lai, 2011). These are then cleaved by Dicer in the cytoplasm and incorporated into typical miRNA silencing complexes (Berezikov et al., 2007; Okamura et al., 2007; Ruby et al., 2007; Sibley et al., 2012; Westholm \& Lai, 2011). The presence of mirtrons may be an evolutionary strategy to diversify miRNA-based gene silencing (Lau \& MacRae, 2009).

\section{MicroRNA 29 family genome}

The miR-29 family is intergenic miRNAs encoded in two gene clusters e.g., one for the primary miR-29a/b1 on chr.7q32, and the other for the primary miR-29b2/c on chr.1q32.2 (Chang et al., 2008; Saini, Griffiths-Jones, \& Enright, 2007). The miR-29b1 and miR-29a precursors are processed from the pri-miR-29a/b1 last intron (Genbank accession EU154353) whilst the miR-29b2 and miR-29c precursors are from the pri-miR-29b2/c last exon (Genbank accession EU154352 and EU154351) (Chang et al., 2008) (Figure 1). 


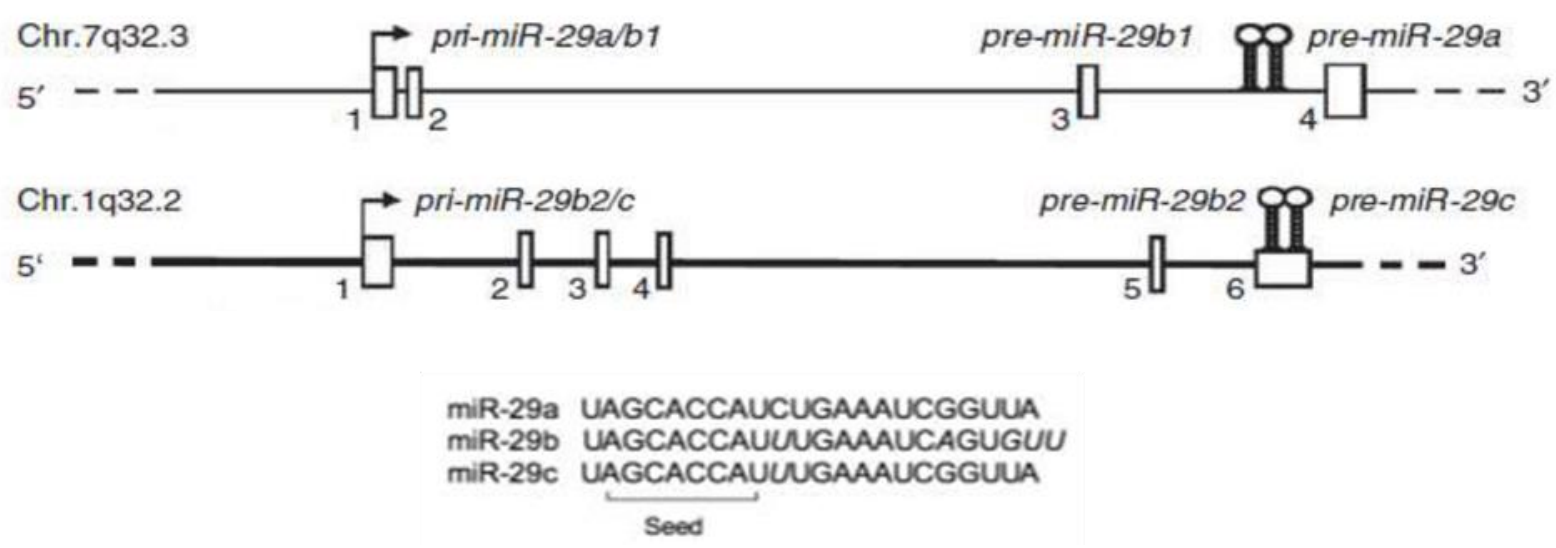

Figure 1. Genomic organization of the miR-29 family

The miR-29 family includes three members miR-29a, miR-29b and miR-29c. The primary pri-29a/b1 is located in chromosome 7 containing pre-29a and pre-29b1. The primary pri-29b2/c is located in chromosome 1 including pre-29b2 and pre-29c. The hairpins indicate the locations of the sequence encoding precursors of miR-29s. Pre-29a and pre-29c will process into mature miR-29a and miR-29c, respectively. Pre-29b1 and pre-29b2 will process into mature miR29b. The mature sequences of the miR-29 family members share identical seed regions. Nucleotides that differ among miR-29s are indicated in italics.

\section{Transcriptional regulation of miR-29 expression}

The miR-29 family precursors are all transcribed as polycistronic primary transcripts (Chang et al., 2008; Mott et al., 2010) upon which various transcriptional regulators e.g., NFkB (Liu et al., 2010; Mott et al., 2010), suppressors (Mott et al., 2010; Parpart et al., 2014), Sp1(Amodio et al., 2012; Liu et al., 2010), Gli (Mott et al., 2010), Yin-Yang-1, Smad3 (Qin et al., 2011), Ezh, H3K27, HDAC1, HDAC3), or inducers (Gli, SRF, Mef2, TCF/LEF, GATA3 (Chou et al., 2013), CEBPA (Eyholzer, Schmid, Wilkens, Mueller, \& Pabst, 2010)), and signaling pathways e.g, Wnt, TGF $\beta, \mathrm{TLR} / \mathrm{NF} \kappa \mathrm{B}, \mathrm{TNF} \alpha / \mathrm{NF} \kappa \mathrm{B}$, hedgehog signalling have been reported to be directly and/or indirectly involved.

\section{Wnt signalling}

Both canonical and non-canonical Wnt signaling was reported to induce the miR-29 family level in different cellular contexts: Wnt3a rapidly induces miR-29 levels in osteoblastic cells (Kapinas, Kessler, \& Delany, 2009; Kapinas, Kessler, Ricks, Gronowicz, \& Delany, 2010) or in muscle progenitor cells (MPCs) (Hu et al., 2014), respectively, at least in part through the two putative TCF/LEF-binding sites in the miR-29a promoter (Kapinas et al., 2010); noncanonical Wnt signaling through Wnt7a/Frizzled 9 resulted in increased expression of only the mature miR-29b but not miR-29a or c or any miR-29b primary or precursor forms in non-small lung cancer cell lines H661 and H15 (Avasarala et al., 2013). In addition, ERK5 and PPAR $\gamma$, key effectors of the Wnt7a/Frizzled 9 pathway, were also observed to be strong inducers of miR-29b expression (Avasarala et al., 2013). 


\section{TGFß/Smad3 signalling}

In contrast to Wnt signaling, TGF $\beta / \mathrm{Smad} 3$ signaling was shown to negatively regulate miR-29 family expression in different cell lines e.g., human aortic adventitial different cell lines e.g., human aortic adventitial fibroblasts (Maegdefessel et al., 2012), renal fibrosis cells (Ramdas, McBride, Denby, \& Baker, 2013; B. Wang et al., 2012), murine hepatic stellate cells (Roderburg et al., 2011), rat hepatic stellate cells (Kwiecinski et al., 2011), human skin fibroblasts (Maurer et al., 2010), human tenon's fibroblast (Li, Cui, Duan, Chen, \& Fan, 2012), human lung fibroblast cell line (Cushing et al., 2011; Yang et al., 2013). The suppressive effect of TGF $\beta / \mathrm{Smad} 3$ signaling on miR-29 expression was partly mediated through a Smad3 binding site in the highly conserved region around $22 \mathrm{~kb}$ upstream of the miR-29b2/c promoter as showed by chromatin immunoprecipitation assay (Qin et al., 2011; Ramdas et al., 2013).

\section{Toll-like receptor (TLR) and TNF $\alpha$ signallings}

Similar to TGF $\beta$, Toll-like receptor (TLR) signaling and TNF $\alpha$ signaling have been shown to mediate suppressive effects on miR-29 family expression. In man, treating human cholangiocarcinoma cells with TLR ligands e.g., TLR3 (Poly (I: C)), TLR4 (LPS), TLR5 (flagellin), TLR6 (MALP-2) showed a significant decrease in the miR-29 level beginning after 4 hours of LPS treatment but increasing to 24 hours (Mott et al., 2010); treating human stellate cells with LPS strongly decreased all miR-29 family expression after 1 hour (Roderburg et al., 2011); treating C2C12 myoblasts with $\mathrm{TNF} \alpha$ substantially reduced miR-29b and miR-29c expression (H. Wang et al., 2008); stimulating the choroidal-retinal pigment epithelial cell line ARPE-19 with $\mathrm{TNF} \alpha$ resulted in significant down regulation of all miR-29s; conversely,

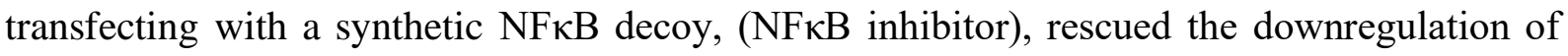
miR-29 by TNF $\alpha$ (J. Cai et al., 2014). The activation of NFאB through TLR signalling with its three binding sites in the miR-29a/b1 cluster promoter $(-561,-110$, and +134$)$ was proven to be the mechanism for the suppression of miR-29a/b1 promoter function (Mott et al., 2010). In mice, miR-29a and miR-29b significantly decreased expression in murine natural killer (NK) cells stimulated with the TLR3 ligand (Poly (I:C)) or phorbol ester (PMA) as well as in splenocytes, NK and T cells of mice infected with L. monocytogenes or Mycobacterium bovis bacillus Calmette-Guérin (Ma et al., 2011). Consistent with the human miRNA, a region about $25 \mathrm{~kb}$ upstream of the murine promoter of miR-29a/b1 contains two NFKB binding sites. The second binding site is more conserved between humans and mouse and it has been shown to be key for suppression of the miR-29a/b1 promoter (Ma et al., 2011).

Importantly, other transcriptional factors, co-operating with NFאB to suppress or induce miR-29 family expression, have also been reported e.g., YY1, Sp1, Ezh, H3K27, HDAC1, HADC3, Mef2, SFR. Forced expression of YY1 in C2C12 lead to a 2-fold decrease of miR29b and miR-29c levels; similarly, siRNA knockdown of YY1 significantly enhanced expression of miRNA expression. ChIP analysis showed that YY1 did not bind to the miR$29 \mathrm{~b} 2 / \mathrm{c}$ locus in cells in the absence of NFKB, suggesting that both pathways are necessary for silencing the miR-29b2/c locus. Amongst 4 putative binding sites of YY1 in highly a conserved region $\sim 20 \mathrm{~kb}$ upstream of miR-29b2/c, only one site is bound by YY1 on ChIP assay whereas all 4 sites produced a binding complex with EMSAs using nucleus extract from $\mathrm{C} 2 \mathrm{C} 12$. Notably, Ezh, H3K27, HDAC1, whose expression is associated with repression of muscle- 
specific genes, and recruited by YY1, was also detected by ChIP assay. In the line of these transcription factors, Mef2 and SFR, well-known for activating muscle genes, were also found to bind to the miR-29b2/c promoter. Again using luciferase reporter assay, a reporter containing a $4.5 \mathrm{~kb}$ fragment spanning YY1, Mef2, SFR binding sites was repressed by YY1 or loss of the YY1 binding site but stimulated with either YY1 knockdown or SRF or Mef2 (H. Wang et al., 2008). In addition, forced expression of Sp1 or NFKB (p65) reduced miR-29b expression; conversely, knockdown of Sp1 or NFKB (p65) by siRNAs resulted in induced miR-29b level (Liu et al., 2010). EMSA assay using probes spanning the -125/-75 miR-29b sequence yielded two major complexes, suggesting $\mathrm{Sp} 1 / \mathrm{NF} \kappa \mathrm{B}$ acts as a repressive complex interacting with an element of the miR-29b enhancer (Liu et al., 2010). Interestingly, histone deacetylase (HDAC) 1 and 3 contribute to the repressor activity of $\mathrm{Sp} 1 / \mathrm{NF} \kappa \mathrm{B}$ on miR-29b expression (Liu et al., 2010). Incubation of HDAC1/HDAC3 with the 32P-labelled probe from the miR-29a/b1 cluster region together with $\mathrm{NF \kappa B}$ p50/p65 and Sp1 showed a delayed and more intense band; HDAC1/3 inhibitors increase miR-29b expression, supporting the interaction of HDAC1 and 3 and $\mathrm{Sp} 1 / \mathrm{NF \kappa B}$ with the miR-29b regulatory sequence (Liu et al., 2010).

\section{Hedgehog signalling}

Similar to other signaling mentioned previously, the hedgehog signaling pathway was also shown to repress miR-29 expression: cells treated with cyclopamine, an inhibitor of Smoothened (a hedgehog signaling component), or transfected with siRNA to knockdown Gli3, the expression of miR-29b increased (Mott et al., 2010). Along with the transcription factors mentioned above, there are other transcriptional factors controlling miR-29 family expression. The serum alpha-fetoprotein (AFP), a membrane-secreted protein associated with poor patient outcome in hepatocellular carcinoma, was reported to inhibit miR-29a expression through facilitating c-MYC binding to the promoter of the pri-miR-29a/b. This conclusion was supported by the inability of AFP to decrease the miR-29a level in the absence of c-MYC protein; c-MYC was abundantly bound to the miR-29a/b1 promoter in the presence of AFP, but did not bind without AFP (Parpart et al., 2014); c-MYC promoter binding protein (MBP), originally described to bind to and repress c-MYC promoter function, up-regulated miR-29b expression by 6 fold in prostate cancer cells (Steele, Mott, \& Ray, 2010). The hematopoietic master transcription factor, CCAAT/enhancer-binding protein- $\alpha$ (CEBPA), was also reported to activate the expression of miR-29a and miR-29b. Forced expression of CEBPA in acute myeloid leukaemic cells leads to two-fold induced expression of the primary miR-29a/b1 and the mature miR-29a and miR-29b whereas the expression of miR-29b2/c primary transcript remained stable. Using luciferase reporter assays, the sequence, having the conserved region spanning -682 bp upstream to +296 bp downstream of the miR-29a/b1 transcriptional start site and containing 6 potential CEBPA sites, was also strongly induced with CEBPA. Among these binding sites, the one located at +15 to +29 bp was identified to be responsible for CEBPAmediated activation of the pri-miR-29a/b1 promoter on ChIP assay (Eyholzer et al., 2010). Another transcriptional factor, GATA3, specifying and maintaining luminal epithelial cell differentiation in the mammary gland, was also found to induce miR-29 expression directly by binding to three GATA3 sites in the miR-29a/b1 promoter. Interestingly, GATA3 can induce miR-29s expression by inhibiting the TGF $\beta$ and NFKB signaling pathways. Additionally, STAT1 (signal transducer and activator of transcription) a transcription factor induced by 
interferon $\gamma$ signalling, was reported to upregulate primary 29a/b1, the pre-29a, pre-29b1, and the mature miR-29a, miR-29b in melanoma cell and T cells (Schmitt, Margue, Behrmann, \& Kreis, 2013).

\section{References}

Ambros, V. (2004). The functions of animal microRNAs. Nature, 431(7006), 350-355.

Amodio, N., Di Martino, M. T., Foresta, U., Leone, E., Lionetti, M., Leotta, M., ... Tassone, P. (2012). miR-29b sensitizes multiple myeloma cells to bortezomib-induced apoptosis through the activation of a feedback loop with the transcription factor Sp1. Cell Death Disease, 3. doi:10.1038/cddis.2012.175

Avasarala, S., Van Scoyk, M., Wang, J., Sechler, M., Vandervest, K., Brzezinski, C., ... Winn, R. A. (2013). hsa-miR29b, a critical downstream target of non-canonical Wnt signaling, plays an anti-proliferative role in non-small cell lung cancer cells via targeting MDM2 expression. Biology Open, 2(7), 675-685. doi:10.1242/bio.20134507

Bartel, D. (2004). MicroRNAs: Genomics, biogenesis, mechanism, and function. Cell, 116(2), 281-297.

Bartel, D. (2009). MicroRNAs: Target recognition and regulatory functions. Cell, 136(2), 215233.

Berezikov, E., Chung, W.-J., Willis, J., Cuppen, E., \& Lai, E. (2007). Mammalian mirtron genes. Molecular Cell, 28(2), 328-336.

Bohnsack, M., Czaplinski, K., \& Gorlich, D. (2004). Exportin 5 is a RanGTP-dependent dsRNA-binding protein that mediates nuclear export of pre-miRNAs. RNA (New York, N.Y.), 10(2), 185-191.

Bossé, G., \& Simard, M. (2010). A new twist in the microRNA pathway: Not Dicer but Argonaute is required for a microRNA production. Cell Research, 20(7), 735-737.

Cai, J., Yin, G., Lin, B., Wang, X., Liu, X., Chen, X., .. . Wu, S. (2014). Roles of NFkappaB miR-29s-MMP-2 circuitry in experimental choroidal neovascularization. Journal of Neuroinflammation, 11(1), 1-21. doi:10.1186/1742-2094-11-88

Cai, X., Hagedorn, C., \& Cullen, B. (2004). Human microRNAs are processed from capped, polyadenylated transcripts that can also function as mRNAs. RNA (New York, N.Y.), 10(12), 1957-1966.

Chang, T. C., Yu, D., Lee, Y. S., Wentzel, E. A., Arking, D. E., West, K. M., . . Mendell, J. T. (2008). Widespread microRNA repression by Myc contributes to tumorigenesis. Nature Genetics, 40(1), 43-50. doi:10.1038/ng.2007.30

Chen, C., Ridzon, D., Broomer, A., Zhou, Z., Lee, D., Nguyen, J., . . Guegler, K. (2005). Realtime quantification of microRNAs by stem-loop RT-PCR. Nucleic Acids Research, 33(20), e179-e179.

Chendrimada, T., Gregory, R., Kumaraswamy, E., Norman, J., Cooch, N., Nishikura, K., \& Shiekhattar, R. (2005). TRBP recruits the Dicer complex to Ago2 for microRNA processing and gene silencing. Nature, 436(7051), 740-744. 
Chou, J., Lin, J. H., Brenot, A., Kim, J. W., Provot, S., \& Werb, Z. (2013). GATA3 suppresses metastasis and modulates the tumour microenvironment by regulating microRNA-29b expression. Nature Cell Biology, 15(2), 201-213. doi:10.1038/ncb2672

Cushing, L., Kuang, P. P., Qian, J., Shao, F., Wu, J., Little, F., . . Lu, J. (2011). miR -29 is a major regulator of genes associated with pulmonary fibrosis. American Journal of Respiratory Cell and Molecular Biology, 45(2), 287-294. doi:10.1165/rcmb.201003230C

Eyholzer, M., Schmid, S., Wilkens, L., Mueller, B. U., \& Pabst, T. (2010). The tumoursuppressive miR-29a/b1 cluster is regulated by CEBPA and blocked in human AML. British Journal of Cancer, 103(2), 275-284. doi:10.1038/sj.bjc.6605751

Friedman, R., Farh, K., Burge, C., \& Bartel, D. (2009). Most mammalian mRNAs are conserved targets of microRNAs. Genome Research, 19(1), 92-105.

Grishok, A., Pasquinelli, A. E., Conte, D., Li, N., Parrish, S., Ha, I., . . Mello, C. C. (2001). Genes and mechanisms related to RNA interference regulate expression of the small temporal RNAs that control C. elegans developmental timing. Cell, 106(1), 23-34.

Hammond, S. M., Bernstein, E., Beach, D., \& Hannon, G. J. (2000). An RNA-directed nuclease mediates post-transcriptional gene silencing in Drosophila cells. Nature, 404(6775), 293296.

Han, J., Lee, Y., Yeom, K.-H., Kim, Y.-K., Jin, H., \& Kim, N. (2004). The Drosha-DGCR8 complex in primary microRNA processing. Genes \& Development, 18(24), 3016-3027.

Hu, Z., Klein, J. D., Mitch, W. E., Zhang, L., Martinez, I., \& Wang, X. H. (2014). MicroRNA29 induces cellular senescence in aging muscle through multiple signaling pathways. Aging (Albany NY), 6(3), 160-175.

Hutvagner, G. (2005). Small RNA asymmetry in RNAi: Function in RISC assembly and gene regulation. FEBS Letters, 579(26), 5850-5857.

Hutvagner, G., \& Simard, M. (2008). Argonaute proteins: Key players in RNA silencing. Nature Reviews. Molecular Cell Biology, 9(1), 22-32.

Hutvagner, G., McLachlan, J., Pasquinelli, A., Bálint, É., Tuschl, T., \& Zamore, P. (2001). A cellular function for the RNA-interference enzyme Dicer in the maturation of the let-7 small temporal RNA. Science, 293(5531), 834-838.

Inui, M., Martello, G., \& Piccolo, S. (2010). MicroRNA control of signal transduction. Nature Reviews. Molecular Cell Biology, 11(4), 252-263.

Kapinas, K., Kessler, C., \& Delany, A. (2009). miR-29 suppression of osteonectin in osteoblasts: Regulation during differentiation and by canonical Wnt signaling. Journal of Cellular Biochemistry, 108(1), 216-224.

Kapinas, K., Kessler, C., Ricks, T., Gronowicz, G., \& Delany, A. M. (2010). miR-29 modulates Wnt signaling in human osteoblasts through a positive feedback loop. Journal of Biological Chemistry, 285(33), 25221-25231. doi:10.1074/jbc.M110.116137

Ketting, R. F., Fischer, S. E., Bernstein, E., Sijen, T., Hannon, G. J., \& Plasterk, R. H. (2001). Dicer functions in RNA interference and in synthesis of small RNA involved in developmental timing in C. elegans. Genes \& Development, 15(20), 2654-2659. 
Khvorova, A., Reynolds, A., \& Jayasena, S. (2003). Functional siRNAs and miRNAs exhibit strand bias. Cell, 115(2), 209-216.

Kim, N. (2005). MicroRNA biogenesis: Coordinated cropping and dicing. Nature Reviews. Molecular Cell Biology, 6(5), 376-385.

Kozomara, A., \& Griffiths-Jones, S. (2011). miRBase: Integrating microRNA annotation and deep-sequencing data. Nucleic Acids Research, 39, D152-D157.

Kwiecinski, M., Noetel, A., Elfimova, N., Trebicka, J., Schievenbusch, S., Strack, I., . . . Odenthal, M. (2011). Hepatocyte growth factor (HGF) inhibits collagen I and IV synthesis in hepatic stellate cells by miRNA-29 induction. PLoS One, 6(9), e24568. doi:10.1371/journal.pone.0024568

Lai, E. (2002). Micro RNAs are complementary to 3' UTR sequence motifs that mediate negative post-transcriptional regulation. Nature Genetics, 30(4), 363-364.

Lau, P.-W., \& MacRae, I. (2009). The molecular machines that mediate microRNA maturation. Journal of Cellular and Molecular Medicine, 13(1), 54-60.

Lee, Y., Jeon, K., Lee, J.-T., Kim, S., \& Kim, N. (2002). MicroRNA maturation: Stepwise processing and subcellular localization. The EMBO Journal, 21(17), 4663-4670.

Lee, Y., Ahn, C., Han, J., Choi, H., Kim, J., Yim, J., . . Kim, N. (2003). The nuclear RNase III Drosha initiates microRNA processing. Nature, 425(6956), 415-419.

Lee, Y., Kim, M., Han, J., Yeom, K.-H., Lee, S., Baek, S., \& Kim, N. (2004). MicroRNA genes are transcribed by RNA polymerase II. The EMBO Journal, 23(20), 4051-4060.

Lewis, B., Burge, C., \& Bartel, D. (2005). conserved seed pairing, often flanked by Adenosines, indicates that thousands of human genes are MicroRNA targets. Cell, 120(1), 15-20.

Li, N., Cui, J., Duan, X., Chen, H., \& Fan, F. (2012). Suppression of type I collagen expression by miR-29b via PI3K, Akt, and Sp1 pathway in human Tenon's fibroblasts. Investigative Ophthalmology \& Visual Science, 53(3), 1670-1678. doi:10.1167/iovs.11-8670

Lim, L., Lau, N., Garrett-Engele, P., Grimson, A., Schelter, J., Castle, J., . . Johnson, J. (2005). Microarray analysis shows that some microRNAs downregulate large numbers of target mRNAs. Nature, 433(7027), 769-773.

Liu, S., Wu, L. C., Pang, J., Santhanam, R., Schwind, S., Wu, Y. Z., . . Marcucci, G. (2010). Sp1/NFkappaB/HDAC/miR-29b regulatory network in KIT-driven myeloid leukemia. Cancer Cell, 17(4), 333-347. doi:10.1016/j.ccr.2010.03.008

Lund, E., Güttinger, S., Calado, A., Dahlberg, J., \& Kutay, U. (2004). Nuclear export of microRNA precursors. Science, 303(5654), 95-98.

Ma, F., Xu, S., Liu, X., Zhang, Q., Xu, X., Liu, M., . . Cao, X. (2011). The microRNA miR29 controls innate and adaptive immune responses to intracellular bacterial infection by targeting interferon-gamma. Nature Immunology, 12(9), 861-869. doi:10.1038/ni.2073

Maegdefessel, L., Azuma, J., Toh, R., Merk, D. R., Deng, A., Chin, J. T., . . Tsao, P. S. (2012). Inhibition of microRNA-29b reduces murine abdominal aortic aneurysm development. Journal of Clinical Investigation, 122(2), 497-506. doi:10.1172/JCI61598 
Martinez, J., Patkaniowska, A., Urlaub, H., Lührmann, R., \& Tuschl, T. (2002). Single-stranded antisense siRNAs guide target RNA cleavage in RNAi. Cell, 110(5), 563-574.

Maurer, B., Stanczyk, J., Jungel, A., Akhmetshina, A., Trenkmann, M., Brock, M., . . Distler, O. (2010). MicroRNA-29, a key regulator of collagen expression in systemic sclerosis. Arthritis Rheum, 62(6), 1733-1743. doi:10.1002/art.27443

Mott, J. L., Kurita, S., Cazanave, S. C., Bronk, S. F., Werneburg, N. W., \& Fernandez-Zapico, M. E. (2010). Transcriptional suppression of mir-29b-1/mir-29a promoter by c-Myc, hedgehog, and NF-kappaB. Journal of Cellular Biochemistry, 110(5), 1155-1164. doi:10.1002/jcb.22630

Okamura, K., Hagen, J., Duan, H., Tyler, D., \& Lai, E. (2007). The mirtron pathway generates microRNA-class regulatory RNAs in Drosophila. Cell, 130(1), 89-100.

Parpart, S., Roessler, S., Dong, F., Rao, V., Takai, A., Ji, J., . . . Wang, X. W. (2014). Modulation of miR-29 expression by alpha-fetoprotein is linked to the hepatocellular carcinoma epigenome. Hepatology, 60(3), 872-883. doi:10.1002/hep.27200

Qin, W., Chung, A. C., Huang, X. R., Meng, X. M., Hui, D. S., Yu, C. M., . . Lan, H. Y. (2011). TGF-beta/Smad3 signaling promotes renal fibrosis by inhibiting miR-29. Journal of the American Society of Nephrology, 22(8), 1462-1474. doi:10.1681/ASN.2010121308

Ramdas, V., McBride, M., Denby, L., \& Baker, A. H. (2013). Canonical transforming growth factor-beta signaling regulates disintegrin metalloprotease expression in experimental renal fibrosis via miR-29. The American Journal of Pathology, 183(6), 1885-1896. doi:10.1016/j.ajpath.2013.08.027

Ro, S., Park, C., Young, D., Sanders, K., \& Yan, W. (2007). Tissue-dependent paired expression of miRNAs. Nucleic Acids Research, 35(17), 5944-5953.

Roderburg, C., Urban, G. W., Bettermann, K., Vucur, M., Zimmermann, H., Schmidt, S., . . . Luedde, T. (2011). Micro-RNA profiling reveals a role for miR-29 in human and murine liver fibrosis. Hepatology, 53(1), 209-218. doi:10.1002/hep.23922

Ruby, G., Jan, C., \& Bartel, D. (2007). Intronic microRNA precursors that bypass Drosha processing. Nature, 448(7149), 83-86.

Saini, H. K., Griffiths-Jones, S., \& Enright, A. J. (2007). Genomic analysis of human microRNA transcripts. Proceedings of the National Academy of Sciences of the United States of America, 104(45), 17719-17724. doi:10.1073/pnas.0703890104

Schmitt, M. J., Margue, C., Behrmann, I., \& Kreis, S. (2013). MiRNA-29: A microRNA family with tumor-suppressing and immune-modulating properties. Current Molecular Medicine, 13(4), 572-585.

Schwarz, D., Hutvágner, G., Du, T., Xu, Z., Aronin, N., \& Zamore, P. (2003). Asymmetry in the assembly of the RNAi enzyme complex. Cell, 115(2), 199-208.

Sibley, C., Seow, Y., Saayman, S., Dijkstra, K., El Andaloussi, S., Weinberg, M., \& Wood, M. (2012). The biogenesis and characterization of mammalian microRNAs of mirtron origin. Nucleic Acids Research, 40(1), 438-448. 
Steele, R., Mott, J. L., \& Ray, R. B. (2010). MBP-1 upregulates miR-29b that represses Mcl-1, collagens, and matrix-metalloproteinase-2 in prostate cancer cells. Genes Cancer, 1(4), 381-387. doi:10.1177/1947601910371978

Suomi, S., Taipaleenmäki, H., Seppänen, A., Ripatti, T., Väänänen, K., Hentunen, T., . . . Laitala-Leinonen, T. (2008). MicroRNAs regulate osteogenesis and chondrogenesis of mouse bone marrow stromal cells. Gene Regulation and Systems Biology, 2, 177-191.

Wang, B., Komers, R., Carew, R., Winbanks, C. E., Xu, B., Herman-Edelstein, M., . . . Kantharidis, P. (2012). Suppression of microRNA-29 expression by TGF-beta1 promotes collagen expression and renal fibrosis. Journal of the American Society of Nephrology, 23(2), 252-265. doi:10.1681/ASN.2011010055

Wang, H., Garzon, R., Sun, H., Ladner, K. J., Singh, R., Dahlman, J., . . . Guttridge, D. C. (2008). NF-kappaB-YY1-miR-29 regulatory circuitry in skeletal myogenesis and rhabdomyosarcoma. Cancer Cell, 14(5), 369-381. doi:10.1016/j.ccr.2008.10.006

Westholm, J., \& Lai, E. (2011). Mirtrons: microRNA biogenesis via splicing. Biochimie, 93(11), 1897-1904.

Yang, T., Liang, Y., Lin, Q., Liu, J., Luo, F., Li, X., . . Zhang, H. (2013). miR-29 mediates TGFbetal-induced extracellular matrix synthesis through activation of PI3K-AKT pathway in human lung fibroblasts. Journal of Cellular Biochemistry, 114(6), 1336-1342. doi:10.1002/jcb.24474

Yi, R., Qin, Y., Macara, I., \& Cullen, B. (2003). Exportin-5 mediates the nuclear export of premicroRNAs and short hairpin RNAs. Genes \& Development, 17(24), 3011-3016.

Zeng, Y., \& Cullen, B. (2004). Structural requirements for pre-microRNA binding and nuclear export by Exportin 5. Nucleic Acids Research, 32(16), 4776-4785. 